1974

\title{
Residency Differentials in Mormon Fertility
}

Brian LeRoy Pitcher

Brigham Young University - Provo

Follow this and additional works at: https://scholarsarchive.byu.edu/etd

Part of the Family, Life Course, and Society Commons, Mormon Studies Commons, Sociology of Religion Commons, and the Women's Studies Commons

\section{BYU ScholarsArchive Citation}

Pitcher, Brian LeRoy, "Residency Differentials in Mormon Fertility" (1974). Theses and Dissertations. 5046. https://scholarsarchive.byu.edu/etd/5046

This Thesis is brought to you for free and open access by BYU ScholarsArchive. It has been accepted for inclusion in Theses and Dissertations by an authorized administrator of BYU ScholarsArchive. For more information, please contact scholarsarchive@byu.edu, ellen_amatangelo@byu.edu. 


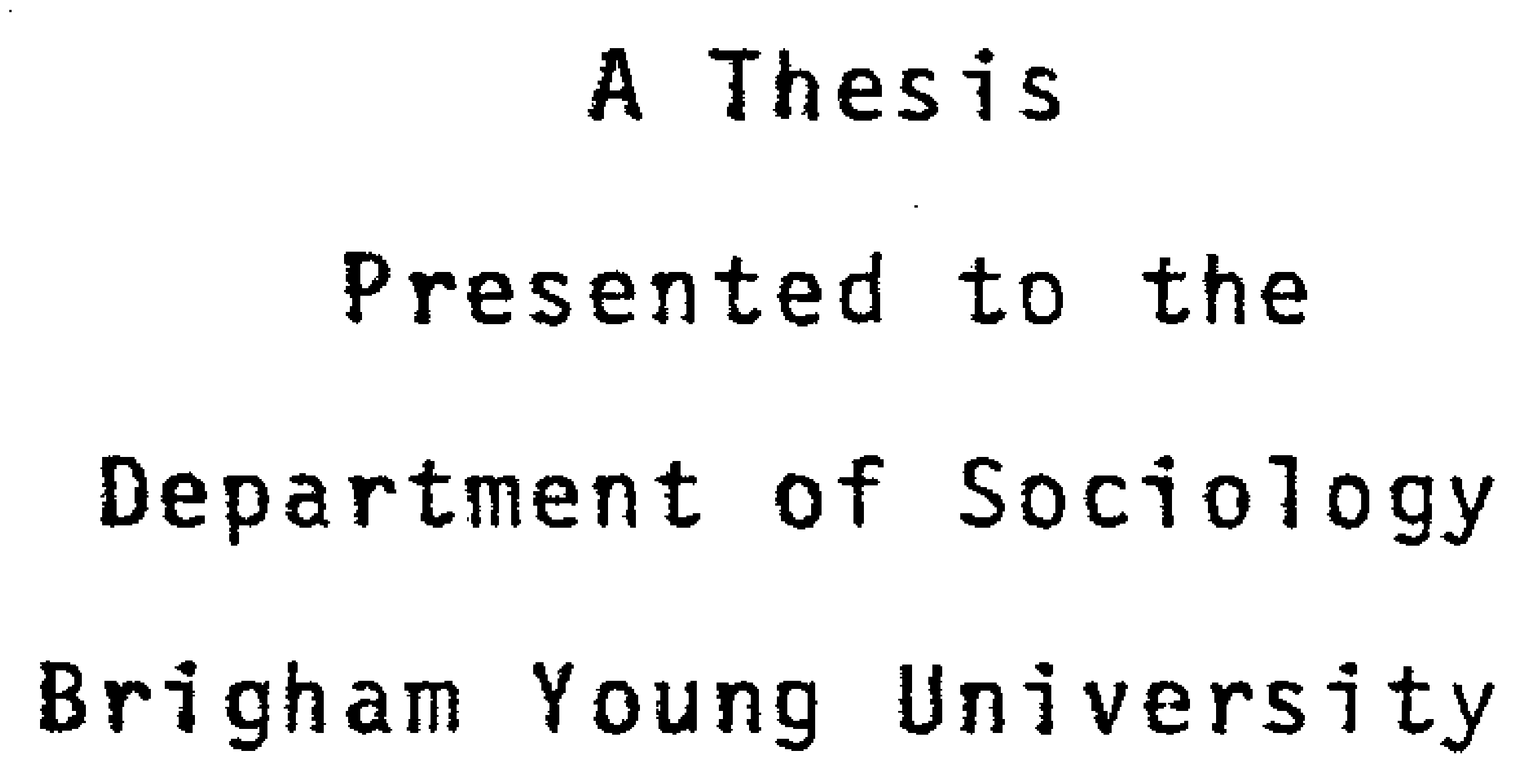

$\iota^{2}$

\author{
In Partial Fulfillment \\ of the Requirements for the Degree \\ Master of Science
}

\author{
by \\ Brian LeRoy Pitcher \\ August 1974
}


This thesis, by Brian LeRoy Pitcher, is accepted in its present form by the Department of Sociology of Brigham Young University as satisfying the thesis requirement for the degree of Master of Science.
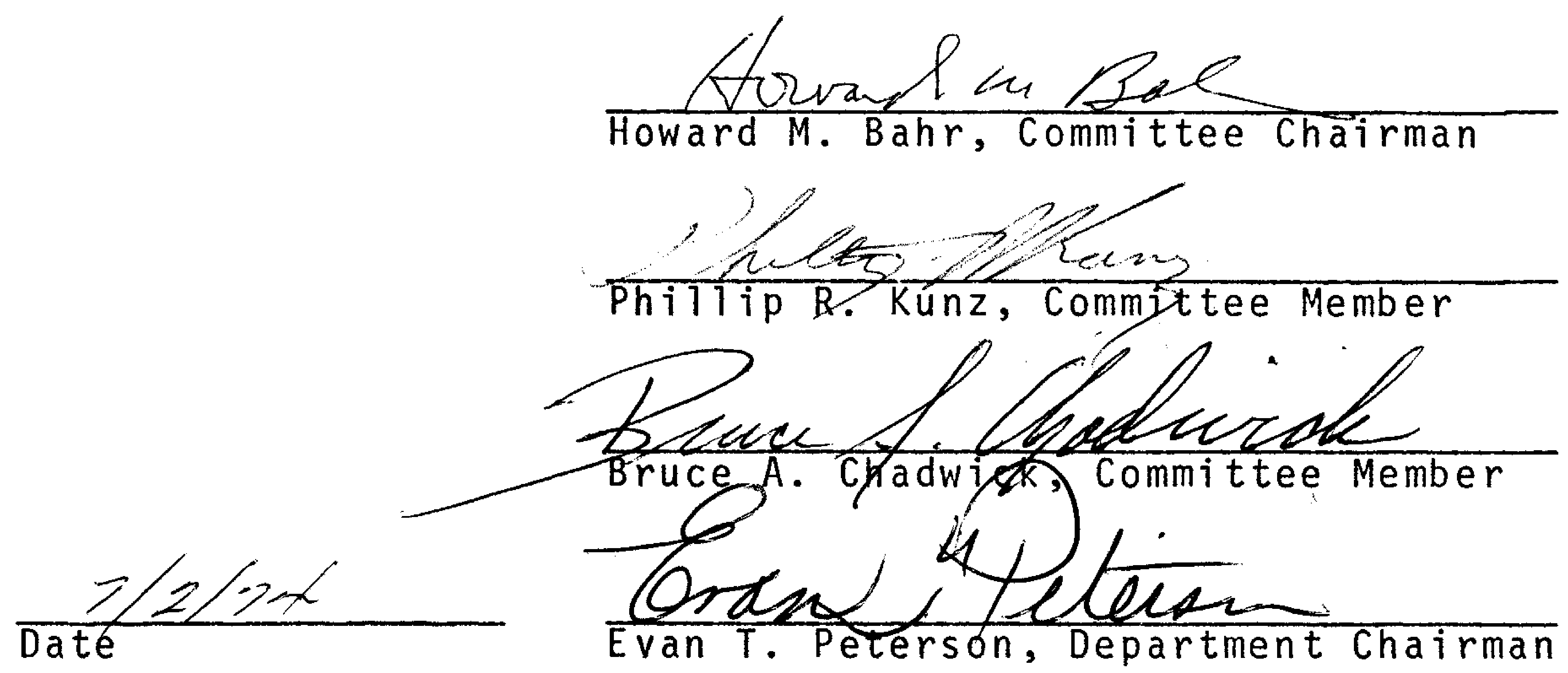
PREFACE

This paper reporting the results of original research conducted by the senior author was published in the journal Population Studies, Volume 28, \#1, p. 43-51, March 1974. In accordance with the option adopted by the Department of Sociology and consistent with Graduate School policy that a paper published in a refereed journal is acceptable in lieu of a thesis for the Master of Science degree, this paper is presented to the Graduate School as fulfilling the Master of Science thesis requirement for Brian LeRoy Pitcher. 


\section{ACKNOWLEDGEMENTS}

This work has been made possible by the National Science Foundation Undergraduate Research Training Project Number GY 9897. Appreciation is expressed to the Genealogical Society of the Church of Jesus Christ of Latter-day Saints for access to their vast collection of world-wide genealogical documents and microfilms. Appreciation is expressed to Franklyn W. Dunford and John D. Bills for their comments and criticisms on an earlier draft of this paper. 
TABLE OF CONTENTS

Page

PREFACE . . . . . . . . . . . . . . . . i

ACKNOWLEDGEMENTS. . . . . . . . . . . . . iv

LIST OF TABLES. . . . . . . . . . . . . . . . vi

RESIDENCY DIFFERENTIALS IN MORMON FERTILITY . . . . 1

SAMPLE AND METHOD . . . . . . . . . . . . . 8

FINDINGS. . . . . . . . . . . . . . 13

DISCUSSION. . . . . . . . . . . . . . . 23

REFERENCES. . . . . . . . . . . . . . 27 


\section{LIST OF TABLES}

Table

1. The Relationship Between Region of Primary Residence and the Number of Children Ever Born to Mormon

Couples............... 14

2. The Relationship Between Region of

Primary Residence and the Number of Children Ever Born to Mormon

Couples with Urban Residence...... 16

3. Comparison Between the Total

Population and the Mormon Sample as to the Total Number of Children

Ever Born per White Married Woman. . . . 


\section{RESIDENCY DIFFERENTIALS IN MORMON FERTILITY}

Most social scientists would probably view religion as one of the more influential institutions in our society. Religious affiliation tends to be an important social characteristic in differentiating human behavior. ${ }^{1}$ Treating religion as a variable in social research, however, has long been hampered by the lack of reliable religious data on a national basis. According to Cannon and Christensen ${ }^{2}$ this data shortage exists

..because of our "separation of the church and
state" ideal, which strictly applied, has prevented
the gathering of religion data in federal censuses
and in most vital statistics registers and also
because denominationally reported statistics have
been so piecemeal and so different in frames of
reference as to make detailed comparison difficult.

This dearth of data, however, has not dampened the enthusiasm of generations of sociologists who have been interested in and investigated the influence of religion on a variety of human behavior. In fact, in recent years the scientific study of religion has increased dramatically as an examination of the journals quickly indicates.

${ }^{1}$ T.R. Ford and G.F. DeJong (eds.), Social Demography, Englewood Cliffs, N.J.: Prentice-Hall, 1970, p. 212.

${ }^{2}$ K.L. Cannon and H.T. Christensen, "Temple Versus Non-Temple Marriage in Utah: Some Demographic Considerations", Social Science, 39, No. 1, (Jan. 1964), p. 27. 
The demographic perspective has numerous points of contact with religious factors. One of these is the contemporary interest in the relationship between religious beliefs and family size. Recently vast quantities of religious fertility research have investigated the impact of race, foreign birth, income, urbanization, occupation, education, migration, and other factors on the relationship between religion and family size. As a result of these studies, it has become quite clear that religion is an important factor in sculpturing completed family size. ${ }^{3}$ In fact, a major conclusion of The Third Child, a volume reporting the findings of a study conducted by the office of Population Research at Princeton University, was that religion is the "...strongest of all major social characteristics in its influence on fertility". 4

Interesting to the contemporary social scientist are the fertility patterns of the Church of Jesus Christ of Latter-day Saints (Mormons) because of their particular ideology which is supportive of high fertility. As Hastings,

${ }^{3}$ L.L. Bumpas and C.F. Westoff, The Latter Years of Child Bearing. Princeton, N.J.: Princeton University Press, 1970 .

${ }^{4}$ C.F. Westoff, R.G. Potter, Jr. and P.G. Sagi, The Third Child - A Study in the Prediction of Fertility. Princeton, N.J.: Princeton University Press, 1963. 
Reynolds, and Canning, ${ }^{5} 0$ 'Dea ${ }^{6}$ and others who have studied the Mormons have emphasized, a combination of theology and cohesive social organization provides strong motivation and support for Mormon parents to have large families. According to what many Mormons accept as official doctrine of the Mormon Church, there are many "spirits who yet await the opportunity to take on mortality and come to earth." Since all these spirits must be born into the world, it is a responsibility of Mormon parents to provide the opportunity by begetting children and properly caring for them until they reach maturity. 7 Past and present Church officials condemn family limitation and regard the high birth rate of Mormons as the best indicator of the Church's prosperity. 8 The extraordinary fruits of this theology and religion have frequently been noted by demographic analysts. one recent pertinent study ${ }^{9}$ indicated that Mormon college graduates might have even higher marital fertility than

${ }^{5}$ D.W. Hastings, C. Reynolds and R. Canning, "Mormonism and Birth Planning: The Discrepancy Between Church Authorities, Teachings and Lay Attitudes", Population Studies, 261 (March, 1972), pp. 19-28.

${ }^{6}$ T. 0'Dea, "The Effects of Geographical Position on Belief and Behavior in a Rural Mormon Village", Rural Sociology, 19 (1954), pp. 358-364; The Mormons. Chicago, I11.: University of Chicago Press, 1964, p. 141.

7J.A. Widstoe, A Rational Theology, 7 th ed. Salt Lake City: Deseret Book Company, 1965, p. 155.

${ }^{8}$ Hastings et al., loc cit.

${ }^{9}$ P.K. Whelpton and Patience Lauriat, "College Study Report - 1956", Population Bulletin 12. 
graduates of Catholic colleges. Westoff and Potvin ${ }^{10}$ in their extensive study reported in the book College Women and Fertility Values found the number of children desired quite predictable for Mormons by using measures of religiousness.

Utah, the center of the Mormon Church, has consistently been at or near the top of the United States for birth rates since its addition to the United States birth registration in 1917. This has occurred in spite of Utah's high ranking among the states in regard to the education of its residents (being number one in 1960). In addition, urbanity ranked number eleven and income ranked number twentyone in 1960. 11 Under the above conditions one would normally expect low fertility rates, but Utah is an exception apparently because of its predominantly (over $70 \%$ ) Mormon population and because of the adherence of the members to their religious values supporting high fertility. The fertility of the Mormons is a very interesting situation worthy of further research and inquiry.

Another unique aspect of the Mormon culture lends even more intrigue to a study of Mormon fertility. During

${ }^{10}$ C.F. Westoff and R.H. Potvin, College Women and Fertility Values. Princeton N.J.: Princeton University Press, 1967 .

11 P.R. Kunz and M.B. Brinkerhoff (eds.), Utah in Numbers. Comparisons, Trends and Descriptions, Provo, Department of Commerce, Bureau of the Census, Volume 1, Characteristics of the Population: Part 1, 1960, xxiti, pp. 1-249. 
the early history of the Mormon Church, their members tended to congregate together in religious communities for both religious and survival reasons. The climax was the great exodus of Latter-day Saint adherents from throughout the world to the isolation of the Salt Lake Valley during the mid and latter nineteenth century. As a consequence, the Mormon Church in Utah was "...not only a religious body, but a total community withdrawn and separated from the larger gentile community". 12

$0^{\prime} \mathrm{Dea}^{13}$ and others theorize that it was primarily because of this isolation that the Mormon sect was able to retain its distinct religious beliefs and practices rather than become dissolved into the greater community as happened to the Molokan community in California at about the same time. 14

In Utah the Mormon culture flourished and large families became the norm. In one southern Utah community Anderson calculated an average of 8.5 children per family during the period 1905 to $1932 .{ }^{15}$ This is an astonishingly

${ }^{12}$ 0'Dea, 1964, op. cit.

$13 \mathrm{~N}$. Anderson, "The Mormon Family", American Sociological Review 2, (1937), pp. 601-608.

${ }^{14}$ p. Young, The Pilgrims of Russian Town. Chicago: University of Chicago Press, 1932 .

15 Anderson, 10c. cit. 
large family size for a U.S. area in the twentieth century. Census data show that in 1910 the average American married woman of completed fertility had 3.8 children. In 1930, the average married woman of completed fertility had only 3.0 children. 16

The high fertility rates and large families meant that due to limited area and resources in Utah, children had to migrate from Utah to other areas as they reached maturity. This movement of young Mormons from Utah poses an interesting problem for Mormon fertility research. Historically the effects of migration have been to undermine traditional ancestral ties and to lower fertility rates. What happens when youth from high fertility traditions migrate? As cultures are brought into collision, differences often break down and homogeneity results. ${ }^{17}$ In such situations the new foreign minority traditionally assimilates the standards and behavior of the native majority. Likewise, Gerhard Lenski ${ }^{18}$ found that intra-societal migration leads to a decrease in religious participation.

Therefore, we would suspect that young Mormon couples moving from the non-industrial, closed, Mormon

${ }^{16}$ United States Department of Commerce, Bureau of the Census, Population Differential Fertility 1940 and 1910, Women by Number of Children ever Born. Washington D.C., 1945 .

${ }^{17}$ A.M. Lee (ed.), Principles of Sociology, New York: Barnes and Noble Inc., 1951, p. 109.

${ }^{18}$ G. Lenski, The Religious Factor. New York: Doubleday and Company Inc., 1961. 
dominated society in Utah to a more industrial community where religion and its attached values are more on the periphery of the culture, would experience a lowering of fertility. As the couple's Mormon strong child-bearing values are confronted in their new environment by the opposing values and influences of a secular world, their fertility will decline.

It is the purpose of this study to take a closer look at Mormon fertility. We are particularly interested in the effect on Mormon fertility of transplanting the Mormon family from the homogeneous Mormon environment in Utah to a more secular non-Mormon cultural environment. Specifically, the guiding hypothesis of this present study will then be that minority Mormon families bearing children in an environment favoring small family size, will tend to have smaller families than will contemporary Mormon families living in predominantly Mormon societies. 


\section{SAMPLE AND METHOD}

The data for this study were collected through the use of family genealogical histories. The Mormon people have been very active in genealogical research because of their religious beliefs concerning the importance of the inter-generational family unit, and as a result have compiled many remarkably complete and accurate family histories. Although this type of data source has rarely been used in social research Yasukichi ${ }^{19}$ proposes it as a possible means of determining early U.S. death rates. Also, in a study conducted in 1965, Bouvier ${ }^{20}$ used a family genealogy to collect data to determine French-Canadian fertility between 1650 and 1950 .

This unique data source was particularly useful in the present research for it provided us with reliable longitudinal family data. Such genealogical records have long been neglected as data sources for generational and longitudinal research.

For the purposes of the study, information was obtained from the family histories of four original Mormon

${ }^{19}$ Y. Yasukichi, Birth Rates of the White Population of the United States: $1800-1860$. Baltimore: John Hopkins Press, 1962 .

20 L.F. Bouvier, "A Genealogical Approach to the Study of French-Canadian Fertility", Sociological Analysis, 25, pp. 148-156. 
pioneers in Utah on 1,001 couples born between the years 1800 and 1940. Each family history contains complete information up to the year 1960. From the entry on each couple in the family history, it was possible to obtain information about the date and place of birth, marriage, and death of each husband and wife. These entries also included the wife's maiden name or the husband's surname and the name, sex, and place of birth and death, if necessary, of each child born to this mating. The entries in some cases also contained the education and occupation of husbands and wives.

As either the husband or the wife of each entry was a descendent of a Mormon pioneer, most entries contained information pertaining to place and date of individual participation rites such as baptism, blessings, and priesthood ordination. This is not to say that all entries were Mormon families. Information on several of the families indicated affiliation with other religions, but as we were only interested in a Mormon sample, we only included in our analysis families where family history information indicated an active affiliation with the Mormon Church.

The information listed for each couple also permitted us to compute the following: the average size of family by both year and location of birth and marriage, the age of the bride and the groom at the time of marriage, the length of marriage, infant mortality rate, the spacing 
of births, the age of wife at the last birth, and the interval between marriage and the first birth. The locations of birth, marriage, and death of the husband and wife, as well as the place where each child was born presented a rough outline of the migratory patterns of a couple. From this outline. we identified a primary region where they had resided during their child-bearing years. With the assistance of census records, we determined whether the couples place of primary residence during their child-bearing years was urban or rural.

occasionally information was lacking. Failure to be able to determine either the length of a marriage, the total number of births during the child-bearing years, or the area of primary residency of each couple automatically resulted in the exclusion of that entry from our analysis. Also, all cases were rejected where, because of death or divorce, the marriage did not last at least 20 years. It was assumed that after 20 years of marriage most couples would have already attained a desired family size or that the wife would be near the end of her fecund period. All couples married before 1940 are treated in the study as completed family units, while those married after 1940 are not.

Inasmuch as the Mormon population is still concentrated mainly in the western United States, we looked, for comparative purposes, at Mormon couples living in three specific regions in the west. These three regions 
are: first, Utah; second, the Intermountain states (Idaho, Wyoming, Colorado, Arizona, and Nevada), and third, the West Coast states (California, Oregon, and Washington).

These regions were differentiated for several reasons. First of all, Utah has consistently very high birth rates, is over $70 \%$ Mormon, and is the center of Mormondom. The Internountain states are fairly homogeneous culturally, have medium to high fertility rates, and have a Mormon population varying between $25 \%$ in Idaho to $6.3 \%$ in Arizona. 21 A common characteristic of these five states is that most of their Mormon population resides in areas which were originally settled by Mormon settlers and are still predominantly Mormon in population. The West coast states have traditionally had low fertility rates, have a low proportion of Mormon population the highest being California where $2 \%$ of the population is Mormon, and are more distinctly separated and isolated from the Mormon center in Salt Lake City.

In terms of our hypothesis, therefore, all couples residing in Utah can be described as residing in a predominantly Mormon society, and all couples residing in the West Coast states can be described as living in an environment foreign to the Mormon culture, favoring small family size.

21 Gilbert W. Scharffs, "An Appraisal of the Current Trends in the Growth and Geographic Distribution of the Mormon Church", An unpublished paper. Provo, Utah: Brigham Young University Press, 1967. 
Because of the characteristics of the Intermountain states, which were identified above, couples having residence in this region cannot be described as living in a society foreign to the Mormon culture and influence. Their level of fertility would, therefore, be expected to be intermediary to those of couples residing in the Utah and the West Coasi areas.

Because our sample is comprised of couples born anytime between the years 1800 and 1940 , we looked at the information separately for each twenty-year time interval. Twenty-seven percent of the couples in our sample were born before 1900, thirty-seven percent between 1900 and 1920 and thirty-six percent after 1920. 


\section{FINDINGS}

As a measure of the level of the fertility of couples, we will look at the total number of children ever born to these couples.

Although extensive analysis of the data for couples married between 1900 and 1919 is somewhat limited by the small number of marriages, there appears to be no appreciable differences among the three regions as to the total number of children ever born to Mormon couples. However, the data for couples married 1920 to 1939 do tend to support our hypothesis that couples residing in the West coast state region would have lower fertility than those in Utah.

Particularly interesting are the differences among the three geographic regions for the category of families having five or more children. Of the families residing in Utah, $43.8 \%$ had five or more children while only $31.8 \%$ of those residing in the Intermountain area and $28 \%$ of those residing in the west coast area had five or more children. This table represents a chi-square of 10.05 which is significant at the .05 level.

Likewise, the data for the marriage years 1940 to 1959 indicate a significant difference between the childbearing habits of Mormons residing in the three regions. 
TABLE 1

THE RELATIONSHIP BETWEEN REGION

OF PRIMARY RESIDENCE AND THE NUMBER

OF CHILDREN EVER BORN TO MORMON COUPLES

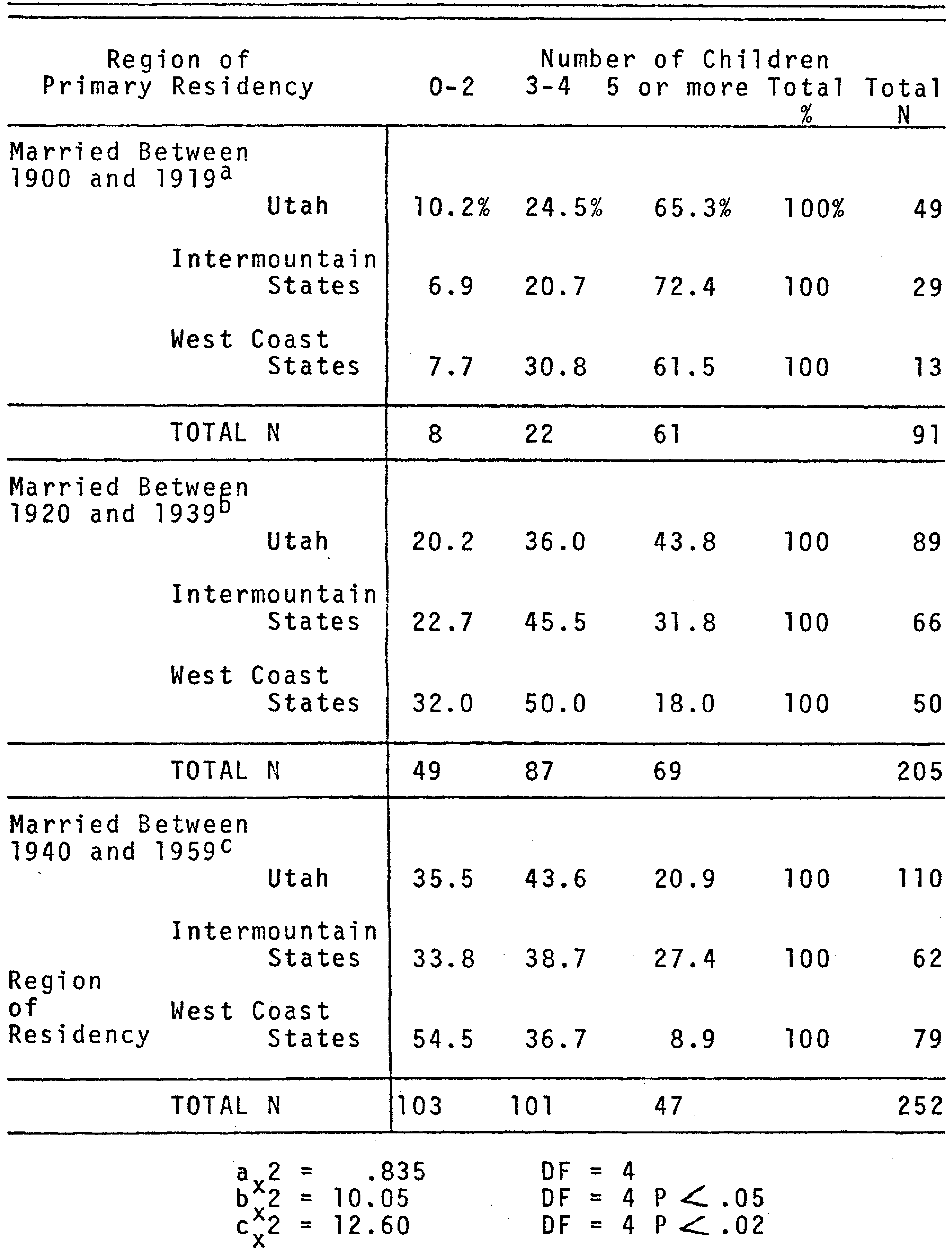


$54.5 \%$ of the families residing in the West coast area had two or fewer children, while the percentage in this category for families in the Intermountain and Utah areas were $33.8 \%$ and $35.5 \%$ respectively. The data on the 1 ast two charts seem to confirm our hypothesis, for the families residing away from the center of the Mormon influence do seem to have smaller families than those in Utah. Not so conclusive, however, is the pattern of fertility for couples in the Intermountain states. Although we only note this pattern at this point, we will comment further on it later in the discussion.

The tendency of city people to have smaller families than farmers and other country people is one of the oldest and most enduring of fertility patterns in the United States. 22 As there are regional differences in urbanity among Utah, the Intermountain states, and the West Coast states, we examined the relationships described in Table 1 while controlling for this factor. When this was done it was found that we did not have a large enough rural sample from the West coast area to compare regional rural differences in Mormon fertility. As a consequence between the region of residency of the couple and the size of family for Mormon families married between 1920 and 1939 and residing in urban areas during their childbearing years.

$22 \mathrm{~J}$. Morris, "New Patterns in U.S. Fertility", Population Bulletin, 20, No. 5 (Sept. 1964), p. 123. 


\section{TABLE 2}

THE RELATIONSHIP BETWEEN REGION OF

PRIMARY RESIDENCE AND THE NUMBER DF CHILDREN

EVER BORN TO MORMON COUPLES WITH URBAN RESIDENCE

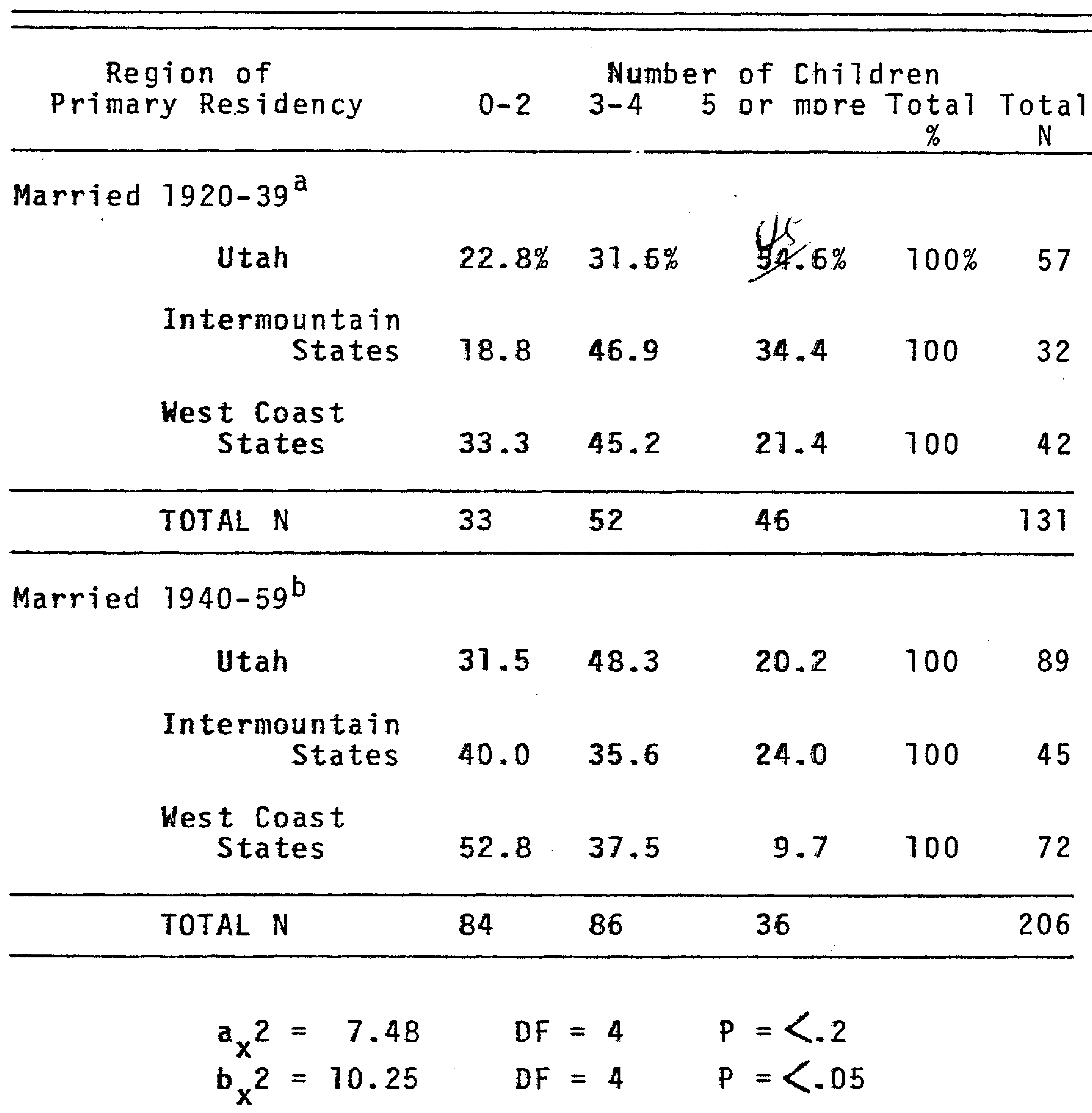

As the table indicates, even when controlling for urban or rural residence a larger proportion of families residing in Utah have five or more children than of families residing in the West coast region $(45.6 \%$ to $21.4 \%)$. 
The same regional differences are evident in the category of families having two or fewer children. Of the families residing in the West Coast states, $33.3 \%$ had two or 1 ess children while only $22.8 \%$ of the Utah families were in this category.

Since these differences are all consistently in the predicted direction, one cannot consider this relationship spurious solely, because the differences are not significant at the .05 level. Nevertheless, there are dangers in drawing too strong of conclusions without further research for tables with small N's.

A significant difference does exist for families living in urban areas and married after 1939.

As indicated only $9.7 \%$ of the Mormon families residing in the West coast area had five or more children as compared with $20.2 \%$ of the families residing in Utah and $24.0 \%$ of those residing in the Intermountain area. Also $52.8 \%$ of the West Coast sample had two or less children. These differences are also significant at the .05 level.

It is interesting to note that in the early part of the twentieth century there were virtually no differences in the fertility patterns of the Mormon residents in these three areas, but that increasing differences did develop as time passed. These differences undoubtedly developed as a result of increased cultural differences among the areas with the West Coast, in particular 
California, becoming industrialized, and secularized much more rapidly than the other areas.

From the above discussion, it is apparent that Mormon families who have migrated to areas where they are in the minority have tended to adopt lower fertility patterns than their contemporaries residing in the center of Mormondom. Whether or not they have forsaken the family size values of their religion to conform to the standards of their new environment is indicated by the following data.

The Census of Population: 1960, Volume 1, Characteristics of the Population provided us with information on the number of children ever born per 1,000 white married women of various ages for each state in the year 1940. This same data was also provided for the years 1950 and 1960 while controlling for urban and rural residence. We were able to calculate a mean figure for each region by taking the mean number of children ever born per married woman for all the states defined as being in each region. By comparing these data with comparable data on the Mormon couples in our study, we were able to see if the Mormons residing in these regions actually followed the fertility patterns of the rest of the population in their region. If we compare, first, the average number of children ever born per white married woman 35-44 years of age in 1940, we find significant differences in all three retions between the women in the Mormon sample and the women in the total population as to the average total number of 
TABLE 3

COMPARISON BETWEEN THE TOTAL POPULATION

AND THE MORMON SAMPLE AS TO THE TOTAL NUMBER

OF CHILDREN EVER BORN PER WHITE MARRIED WOMAN

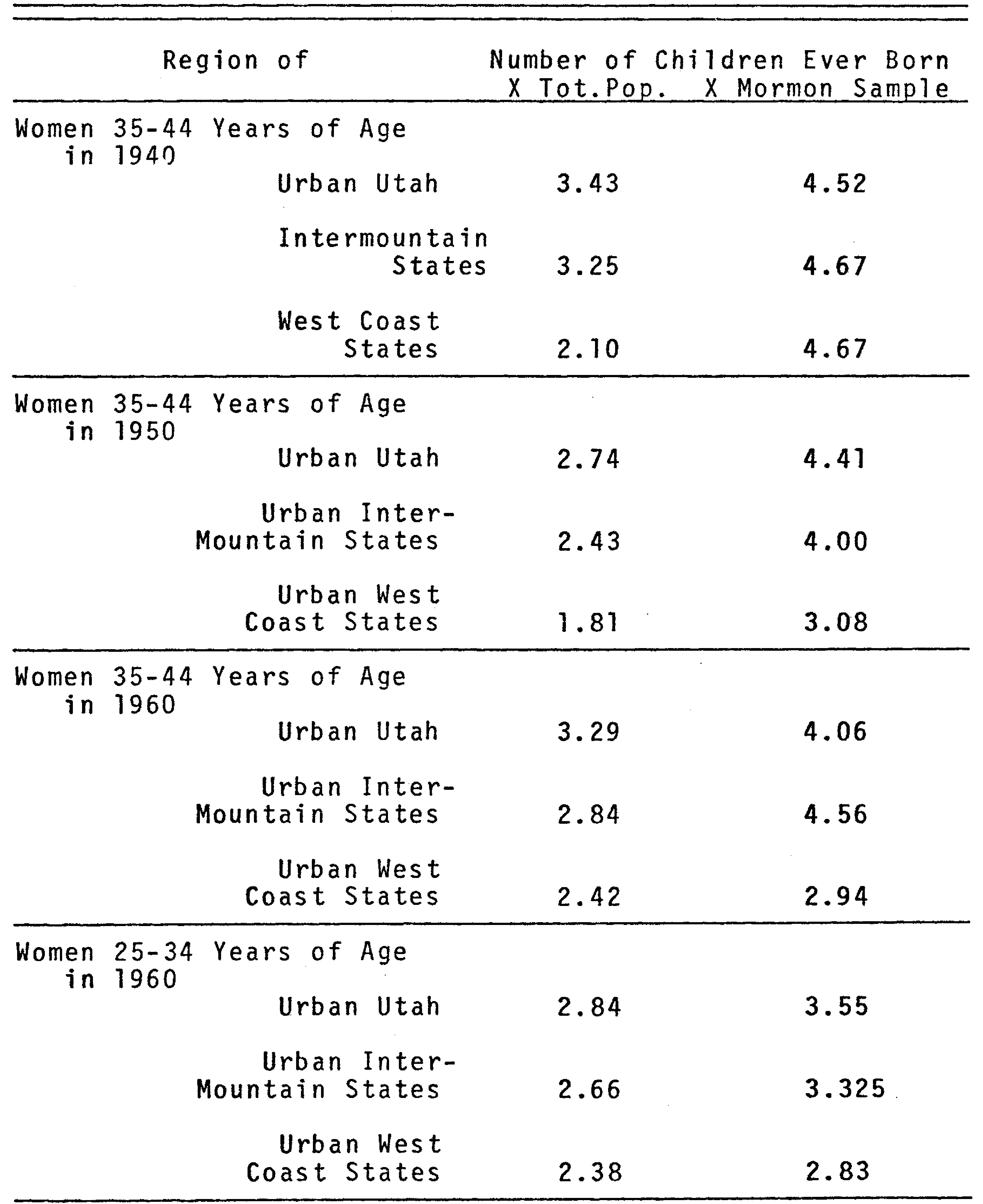


children ever born them. Although there were differences among the three regions in the mean number of children born per married woman in the total population, there were essentially no differences among the regions as to the average number of children born to Mormon couples.

The census data for 1940 did not differentiate between urban or rural residence in presenting the mean number of children ever born per married white woman. Because the census data for 1950 and for 1960 did give this information, we were able to compare the mean number of children while controlling the urbanity. The next three parts of Table 3 , then, present data only for urban residents.

It is evident that for the cohort of Mormon women who were 35-44 years of age in 1950 a relationship does exist between family size and place of residence. Mormon couples on the West coast have on the average smajler completed families than couples residing in the Intermountain or Utah areas. This cohort of women began their families during the depression and the early war years, thus, possibly partially explaining why the number of children born per married woman in the total population was so low. Yet, though the fertility trends by region of the women in our sample do follow those of the total population, the data indicate that the Mormon women in all three regions had comparatively very large family sizes for the region in which they resided. Apparently they were less affected by the family limiting pressures and influences of the 
depression than their non-Mormon contemporaries.

Essentially the same patterns appear for the cohort of 35-44 year old women in 1960 with the Mormon sub-population in all regions still having larger families than the rest of the population. However, there appears with successive cohorts to be a trend toward diminishing the differences between the Mormons and the rest of the population in regards to completed family size.

Especially interesting is the high mean number of children ever born to Mormons in the Intermountain states region. In many cases in previous tables it can be noted that the fertility of the Mormon sample from the Intermountain area often approximates and sometimes, such as in this case for women 35-44 in 1960, exceeds the fertility of the Utah sample. This can possibly be explained by the possibility that most of our sample from this region resided in predominantly Mormon communities that were originally settled by Mormons. 0 'Dea ${ }^{23}$ in a study of rural Mormon villages in Utah and New Mexico found the village in the latter area to be less secularized and more orthodox than those in Utah itself. This he explained as being due to the fact that Mormons away from the center of Mormondom had less interaction with Church leaders and therefore could not "take the Church for granted." Speaking of the New Mexico community he states that "...given strong belief, peri-

$$
\text { 23 LOC cit., } 1954, \text { p. 38-39. }
$$


pheral position and isolation can act to strengthen belief in group solidarity based on the consenses of common belief." This may help explain the finding that the Mormon sample from this region and the sample from Utah have comparable fertility rates.

For married women between the ages of 25 and 34 years in 1960, we find the same patterns as presented in the rest of the table. There are differences among the Mormon sample in number of children ever born according to the area of the couple's residence but in all cases and in all regions the mean number of children for the Mormon sample is considerably above that of the total population.

From Table 3 it is apparent that Mormons in each region have maintained fertility patterns that are well above the standards of their environment. This reflects the importance of the influence of religion on family size in the Mormon culture. These findings indicate that although the region of residence of the couple for various reasons does affect the completed family size of the Mormon couple, this environmental influence does not overshadow the influence of their religion. 


\section{DISCUSSION}

It should be recognized that our choice of a research source has, at least to a certain extent, limited the depth of this analysis. No claim is made that the data obtained from the family genealogies would be as representative of the total Mormon population or as accurate as those derived from census or vital statistics data, if they were available in this field of study. Our use of family genealogies does, however, provide us with a reasonable and representative sample of the Mormon ethnic group, an accurate picture of their family characteristics, and a very good data source for obtaining generational and migratory information of the type needed in the present research.

Unfortunately, we were not able to deal in an indepth way with the complexity of factors that aid in the explanation of the phenomenon that we have observed in this research. For example, social scientists 24,25 have noted the high fertility of new farm immigrants to cities. Because movement of youth from Utah has been from agricultural areas to urban, industrial centers, our sample may be comprised of many first generation farm immigrants, and there-

${ }^{24}$ D. Goldberg, "The Fertility of Two Generation Urbanites", Population Studies, 12 (March 1959), p. 218.

25 Morris, 10c. cit., p. 124. 
fore, the fertility patterns we found may be abnormally high for urban areas. As we were not able to obtain data on this, we can only estimate that its impact on our data partially accounts for the high fertility rates found.

Also, we were not able to determine the education and occupation of many of the parents in the sample, and therefore, we were not able to investigate their influences on our findings. Hastings, Reynolds and Canning did note that even among Mormons with high educational attainment, secularization works quite slowly and we probably could assume that the same would be true of the relationship between education and fertility. ${ }^{26}$ It is interesting to note that in a study reported by Westoff, The Third Child, religion was determined to be a far more important predictor of fertility than was occupation. 27 Also in the "Family Growth in Metropolitan American Study", 28 religion was found to be a better indicator of family size than was social class. Although we assume that we have random selections of educational levels and occupations within our sample, some differences within our sample may in some degree account for the regional differences we found in Mormon fertility.

${ }^{26}$ Hastings, Reynolds and Canning, loc. cit., p. 28. 27 Westoff, et.al. op.cit.

${ }^{28}$ C.F. Westoff, P.G. Sagi and E.G. Mishler, Family Growth in Metropolitan America. Princeton, N.J.: Princeton University Press, 1961. 
It was, likewise, not possible to measure and therefore control for the degree of orthodoxy or religiosity of our sample population. 0'Dea, ${ }^{29}$ Anderson ${ }^{30}$ and Done 31 a 1 hypothesize that Mormons moving from Utah to non-Mormon environments would suffer from an increase in apostacy and less orthodoxy. Also, there was the possibility that the migration from Utah was in some degree selective with the faithless being more willing and eager to move away from the center of the Mormon influence. Since DeJong found religious fundamentalism to be significantly positively related to fertility, especially for metropolitan populations, it is possible that the lower fertility rates of the Mormon couples residing in the West coast states may indicate either, lower fertility among active, religious members or less religious fundamentalism and orthodoxy among this West Coast group of couples than among the couples in other areas. $^{32}$

This study does strongly indicate that in spite of ancestral attachments and religious ties, the culture of the alien secular environment eventually affected the

$$
\begin{aligned}
& { }^{29} 0 \text { 'Dea, } 1964, \text { op. cit., p. } 267 . \\
& { }^{30} \text { Anderson, 10c. cit., p. } 607 . \\
& { }^{31} \text { G. B. Done, "A Study of Mormon-Gentile Inter- }
\end{aligned}
$$
marriages in Los Angeles". An unpublished dissertation at the University of Southern California, 1937.

${ }^{32}$ G. F. DeJong, "Religious Fundamentalism, SocioEconomic Status and Fertility Attitudes", in T.R. Ford and G. F. DeJong (eds.), Social Demography, pp. 226-235. Englewood Cliffs, N.J.: Prentice-Ha11, 1970. 
behavior of Mormon immigrants. As was hypothesized, our data show that, especially in recent years, Mormon couples residing in a non-Mormon environment have significantly smaller families than Mormon couples residing in Utah. Urban-living and co-mingling with non-Mormons are perhaps factors in the lowering of fertility among West Coast Mormons. There is, however, evidence that transplanted Mormons do remain loyal to their religious beliefs. This is supported by the data which indicates that their fertility rates are consistently above the rates of the area in which they reside. The findings of the present study have been basically descriptive. We have suggested and discussed various variables and influences on the phenomena observed. We suggest that further research should include a consideration of religion while examining the influence of factors such as education, occupation, social class and mobility, migration, urbanity, etc., on the traditional values of the Mormon church, while controlling regional sub-groups within the Mormon community both those residing in Utah and the inter-mountain west and those residing in other parts of the United States and in other countries. 


\section{REFERENCES}

Anderson, N. "The Mormon Family". American Sociological Review, Vol. 2, $1937, \mathrm{pp} .601-608$.

Bouview, L.F. "A genealogical Approach to the Study of French-Canadian Fertility". Sociological Analysis, Vo1. 26, 1965, pp. 148-156.

Bumpas, L.L. and Westoff, C.F. The Latter Years of Child Bearing. Princeton, N.J.: Princeton University Press, 1970 .

Cannon, K.L. and Christensen, H.T. "Temple Versus NonTemple Marriage in Utah: Some Demographic Considerations". Social Science, Vol. 39, No. 1, (Jan. 1964): pp. $26-33$.

DeJong, G.F. "Religious Fundamentalism, Socio-Economic Status and Fertility Attitudes" in T.R. Ford and G.F. DeJong (eds.). Social Demography, Englewood Cliffs, N.J.: Prentice-Hall, 1970, pp. 226-235.

Done, G.B. "A Study of Mormon-Gentile Inter-Marriages in Los Angeles". An unpublished dissertation, University of Southern California, 1937.

Ford, T.R. and DeJong, G.F. (eds.). Social Demography. Englewood Cliffs, N.J.: Prentice-Hal1, 1970, p. 212.

Hastings, D.W., Reynolds, C. and Canning, R. "Mormonism and Birth Planning: The Discrepancy Between Church Authorities, Teachings and Lay Attitudes". Population Studies, Vol. 26, No. 1, (Mar. 1972): p p. 1928 .

Kunz, P.R., and Brinkerhoff, M.B. (eds.). Utah in Numbers: Comparisons, Trends and Discriptions. Provo, Utah: Brigham Young University Press, 1969.

Lee, A.M. (ed.). Principles of Sociology. New York: Barnes and Noble Inc., 1951.

Lenski, G. The Religious Factor. New York: Doubleday and Company, Inc.; 1967 . 
Morris, J. "New Patterns in U.S. Fertility". Population Bulletin, Vol. 20, No. 5, (Sept. 1964): pp. 113-139.

O'Kea, T. "The Effects of Geographical Position on Belief and Behavior in a Rural Mormon Village". Rural Sociology, Vo1. 19, 1954, pp. 358-364.

0'Kea, T. The Mormons. Chicago, 111.: University of Chicago Press, 1964 .

Scharffs, Gilbert W. "An Appraisal of the Current Trends in the Growth and Geographic Distribution of the Mormon Church". An unpublished paper, Provo, Utah: Brigham Young University Press.

United States Department of Commerce. Bureau of the Census; Population Differential Fertility 1940 and 1910 , Women by Number of Children Ever Born. Washington, D.C., 1945 .

Westoff, C.F., Sagi, P. and Mishler, E.G. Family Growth in Metropolitan America. Princeton, N.J.: Princeton University Press, 1961.

Westoff, C.F., Potter, R.G., Jr., and Sagi, P.G. The Third Child - A Study in the Prediction of Fertility.

Princeton, N.J.: Princeton University Press, 7963.

Westoff, C.F. and Pottin R.H. College Women and Fertility Values. Princeton, N.J.: Princeton University Press, 1967 .

Widstoe, J.A. A Rational Theology. 7 th ed. Salt Lake City: Deseret Book Co., 1965.

Whelpton, P.K. and Lauriet, P. "College Study Report 1956". Population Bulletin XII, 1956.

Yasukichi, U. Birth Rates of the White Population of the United States: 1800-1860. Baltimore: John Hopkins Press, 1962 .

Young, P. The Pilgrims of Russian Town. Chicago: University of Chicago Press, 1932. 


\title{
RESIDENCY DIFFERENTIALS IN MORMON FERTILITY
}

\author{
Brian LeRoy Pitcher \\ Department of Sociology \\ M.S. Degree, August 1974
}

\section{ABSTRACT}

Although one of the most consistent findings of recent fertility research is the convergence of the religious differentials in fertility, little data have been analyzed to discover the Mormon fertility trends and differentials. This study, based on data obtained on 1,001 Mormon couples, is concerned with describing the effects that the dispersion of Mormon families from the Mormon center in Utah to surrounding areas with various social conditions is having on the fertility of the relocated Mormon families. Data presented clearly show that such families do, on the average, have a lower fertility than do their Mormon contemporaries residing in the homogeneous Mormon society in Utah. They probably compromise their religious obligations of having children to the contradicting demands of their new environment. Their loyalty to these religious beliefs, however, is confirmed by data which show that they tend to have

larger families in their new environment than do their nonMormon neighbors.

COMMITTEE APPROVAL:
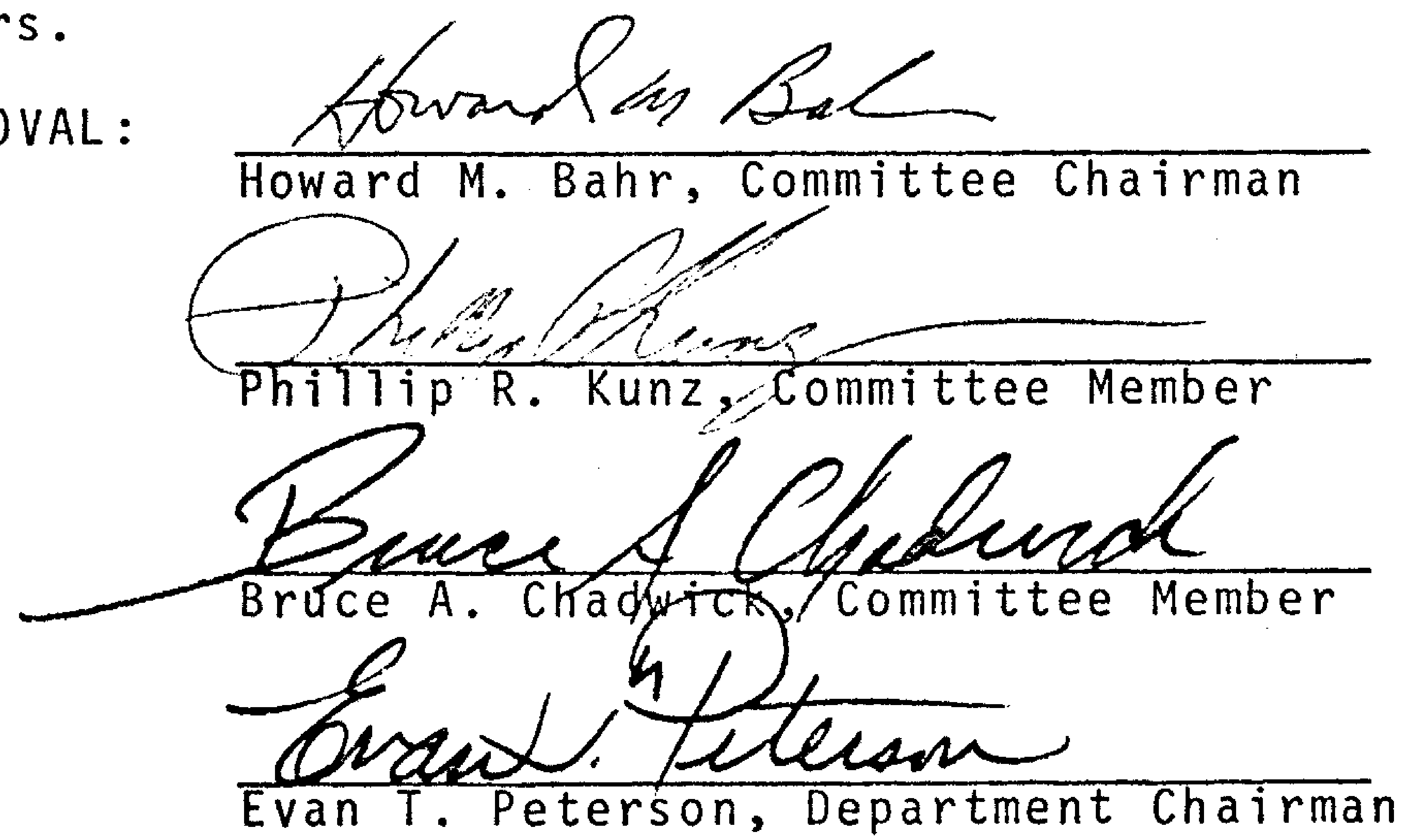